\title{
Minority Use of a National Cancer Institute-Designated Comprehensive Cancer Center and Non-specialty Hospitals in Two Florida Regions
}

\author{
Dawood H. Sultan • Jemal Gishe • Angella Hanciles • \\ Meg M. Comins • Claire M. Norris
}

Received: 7 October 2014 /Revised: 4 December 2014 / Accepted: 5 January 2015 /Published online: 29 January 2015

(C) W. Montague Cobb-NMA Health Institute 2015

\begin{abstract}
Purpose To examine cancer treatment disparities at a National Cancer Institute-designated comprehensive cancer center (NCI-CCC) and non-specialty hospitals.

Materials and Methods Florida hospital discharge datasets were used. ICD9-CM codes were used to define patients with female reproductive organ cancers (FROC), male reproductive organ cancers (MROC), and OTHER cancer diagnoses. A total of 7462 NCI-CCC patients and 21,875 non-specialty hospital patients were included in the statistical analysis. Data analysis was conducted in SAS 9.2.
\end{abstract}

D. H. Sultan $(\bowtie) \cdot$ M. M. Comins

Department of Health Policy and Management, College of Public Health, University of South Florida,

13201 Bruce B. Downs BLVD, MDC 56,

Tampa, FL 33612-3805, USA

e-mail: dsultan@health.usf.edu

D. H. Sultan

e-mail: sultan.nuba@gmail.com

M. M. Comins

e-mail: comins.meg@gmail.com

J. Gishe $\cdot$ A. Hanciles

Department of Epidemiology and Biostatistics,

College of Public Health, University of South Florida,

13201 Bruce B. Downs BLVD, MDC 56,

Tampa, FL 33612-3805, USA

J. Gishe

e-mail: jgishe@health.usf.edu

A. Hanciles

e-mail: ahancile@health.usf.edu

C. M. Norris

Louisiana Board of Regents,

1201 N. Third St., Suite 6-200, Baton Rouge, LA 70802, USA

e-mail: clairexula@gmail.com
Results Increases in age reduced the odds of receiving treatment at the NCI-CCC. Male patients were more likely than female patients to be treated at the NCI-CCC. Age-adjusted odds of African American and Hispanic out/inpatients being treated at the NCI-CCC were significantly lower than those of White out/inpatients. Only patients with workers' compensation, charity, or other insurance had higher odds of being treated at the NCI-CCC. The odds of minority patients receiving outpatient treatment at the NCI-CCC declined after 2005. The odds of receiving inpatient treatment at the NCI-CCC significantly increased after 2006.

Conclusions More targeted outreach by the NCI-CCC is required. However, we expect the creation of local Accountable Care Organizations (ACOs) to reduce the numbers of minority and older patients at the NCI-CCC. Coordinated quality care at ACOs implies a potential for retaining the patient market share held by non-specialty hospitals and a potential for increased demand for ACO care by minority and older patients.

Keywords Comprehensive Cancer Center · Minority · African American · Hispanic

\section{Introduction}

Through its designated cancer centers program, the National Cancer Institute (NCI) recognized 68 regional healthcare centers as centers of excellence in cancer research and patient treatment $[1,2]$. Of these, 41 are comprehensive cancer centers [2]. A comprehensive cancer center "must demonstrate reasonable depth and breadth of research in each of three major areas: laboratory, clinical, and population-based research, as well as substantial transdisciplinary research that bridges these scientific areas. In addition, a comprehensive center must also demonstrate professional and public education and outreach 
capabilities, including the dissemination of clinical and public health advances in the communities it serves." [2] NCIdesignated cancer centers are credited with providing multidisciplinary and state of the art cancer treatment and expertise in rare cancers [2]. Patients treated at NCI-designated cancer centers are shown to experience lower cancer surgical mortality and superior treatment outcomes [3-5]. However, the use of treatment services provided by $\mathrm{NCI}$-designated comprehensive cancer centers (NCI-CCCs) by ethnic minority patients has not been extensively studied [6]. This is more so in the case of the African American and Hispanic minority patients considered in this study. One of the only two studies which examined minority use of NCI cancer centers relied on a sample of African American Medicare patients only and did not account for whether the patients were treated at an NCI-designated cancer canter or a NCI-CCC [7]. The other study examined the use by White, Black, Hispanic, and Asian/Pacific Islander cancer patients in California but, similarly, did not clearly differentiate them in terms of whether their treatments were received at an NCI-designated cancer center or a NCI-CCC [6]. To our knowledge, minority use of NCI-CCCs is not studied in detail.

Using patient hospital discharge records from an all-payer, all-provider, all-age, all-gender, racially, and ethnically diverse dataset, this study attempts to determine (1) whether or not the racial/ethnic and age distributions of cancer patients in a NCICCC differ from distributions in non-specialty hospitals in healthcare service regions surrounding the NCI-CCC and (2) whether or not patient demographics, insurance status, cancer diagnosis, location, and time of cancer treatment influence minority use of NCI-CCC. We mainly hypothesize that patient age, gender, ethnicity, geographic location, insurance status, type of diagnosis, and year of diagnosis were important determinants of whether or not African American and Hispanic cancer patients use a NCI-CCC for cancer treatment and care.

This study falls within the body of scientific research which attempts to determine the role of healthcare institutions, healthcare providers, and individual patients in the creation of ethnic and racial disparities in access to and utilization of available cancer treatment and care services. Outlining disparities in cancer treatment and care service use and the associations of patients' demographic, socioeconomic, and other characteristics with access to quality cancer care are important tools for informing community outreach to improve minority access to NCI-CCCs and for adding to the scientific evidence relevant to the overall understanding of disparities in cancer treatment.

\section{Materials and Methods}

Sources of Data

Though statewide cancer statistics are available from the Florida Cancer Data System [7], we chose to use in our analysis data provided by the Florida Agency for Health Care Administration (AHCA). We are more familiar with AHCA datasets and have used them in prior research. Also, the datasets were readily available at the time this manuscript was conceived. Outpatient data (for the years 2005-2010) and inpatient data (for the years 2006-2011) were obtained from service information in the Florida hospital discharge datasets, maintained by the AHCA Office of Data Dissemination and Communication. The Agency for Health Care Administration was statutorily created by Chapter 20 of the Florida Statutes as the primary health policy and healthcare planning agency for the state. Among other responsibilities, the agency regulates the licensure of the state's 45,000 healthcare facilities and maintains and shares healthcare data through the Florida Center for Health Information and Policy Analysis [8]. AHCA's Florida hospital discharge datasets contain information on all-payers, all-providers, all-ages, all-gender, and patient race/ethnicity. Patient discharge records from healthcare facilities reporting to AHCA contain International Classification of Diseases, Ninth Revision, Clinical Modification (ICD9-CM) codes indicating the primary diagnosis for an admission and the primary procedure performed during the index admission. The datasets also include an identifier of the healthcare facility region and a unique identification number for each hospital and each index admission. At the time of statistical analysis, outpatient data were available only up to 2010 . Also, prior to 2005 , the inpatient dataset was in a format which we could not import into the statistical software used for data analysis. These are the reasons why the datasets presented in this manuscript have different start/end dates. However, the different dates have no effect on the substantive interpretations provided in this paper. The paper dealt separately with inpatients and outpatients who could be examined at the same or different time periods.

\section{Study Population}

ICD9-CM codes were used to identify patients with a primary diagnosis of female reproductive organ cancer (FROC) [ICD9-CM codes 179, 180, 182, 183, and 184], male reproductive organ cancer (MROC) [ICD9-CM codes 185, 186, 187], and OTHER cancer diagnoses including FROC-related malignant neoplasm of female breast [ICD9-CM codes 174.09], MROC-related malignant neoplasm of male breast [ICD9CM codes 175.0-9], and malignant neoplasm of trachea bronchus and lung [ICD9-CM codes 162.0-9]. These codes define "cancers that are diagnosed with the greatest frequency in the United States, excluding nonmelanoma skin cancers" [9]. Since this study examines patient distributions and odds of cancer treatment by hospital type (NCI-CCC versus non-specialty) in two healthcare service regions surrounding the NCICCC, we included only patients served at the NCI-CCC and reporting hospitals in Florida health regions 5 and 6 . These 
regions comprise the following counties: Pinellas, Pasco, Hardee, Highlands, Hillsborough, Manatee, and Polk. All outpatients and inpatients from regions 5 and 6 and the NCI-CCC with FROC, MROC, and OTHER diagnoses identified for this study were included in the analysis. All third-party payers charged for index admissions were also included.

A total of 29,337 patients met the inclusion criteria: (1) assigned ICD9-CM code indicating either a FROC, MROC or OTHER diagnosis for index admission at the NCI-CCC, or a reporting non-specialty hospital in Florida regions 5 and 6 and (2) receiving cancer treatment between the years 2005 and 2010 as outpatient and 2006 and 2011 as inpatient. Of these, a total of 7462 were NCI-CCC patients (5384 outpatients and 2078 inpatients) and the remaining 21,875 were non-specialty hospital patients (12,639 outpatients and 9236 inpatients).

\section{Study Variables}

The datasets used in this study included information on patient age, gender, ethnicity, type of health insurance, cancer diagnosis, year of cancer treatment, the county of the cancer treatment facility. In the statistical analysis conducted on the outpatient and inpatient datasets, patient age was measured in years. Patient gender was measured as a binary $(0,1)$ variable. Patient race/ethnicity was measured as a four-item (1-4) categorical variable (Black, White, Hispanic, and Other, respectively). In this study, the African American (interchangeably identified as Black) patients in the data analysis did not include self-identified Black Hispanics. Likewise, White patients in the analysis did not include self-identified White Hispanics. Patients identified as Hispanic, White Hispanic, or Black Hispanic were grouped under the Hispanic ethnic designation. All patients who reported another race/ethnicity were defined as Other. The Other race/ethnicity category did not include Black, White, Hispanic, Black Hispanic, or White Hispanic patients. Insurance status was defined as a five-item categorical variable: (1) indicating Medicare, Medicare Health Maintenance Organization (HMO), and Medicare Preferred Provider Organization (PPO) (referred to as Insur1); (2) indicating Medicaid and Medicaid HMO (referred to as Insur2); (3) indicating commercial insurance, commercial HMO, commercial PPO, and self-pay (referred to as Insur3); (4) indicating workers' compensation, charity, and other (referred to as Insur4); and (5) indicating CHAMPUS, VA, state/local government and Kidcare (referred to as Insur5). Cancer treatment years were assigned 1-6 values for outpatient and inpatient datasets, respectively. The location of the cancer treatment facility is measured as a seven-item categorical variable: (1) indicating Highlands County, (2) indicating Hillsborough County, (3) indicating the NCI-CCC, (4) indicating Manatee County, (5) indicating Pasco County, (6) indicating Pinellas County, and (7) indicating Polk County. Location identifiers 1, $2,4,5,6$, and 7 were collapsed into a single category which was contrasted with the NCI-CCC to create a binary $(0,1)$ variable indicating whether a treatment facility was located in Florida Region 5 and 6 or the NCI-CCC. A binary $(0,1)$ variable measuring whether a patient was treated at a nonspecialty hospital or at the NCI-CCC was used as dependent variable for logistic regression models fitted to the outpatient and inpatient datasets.

\section{Statistical Analysis}

The independent samples $t$ test was conducted to compare the mean age of outpatients and inpatients at the NCI-CCC and non-specialty hospitals. Chi-square test was used to compare the use of the NCI-CCC and local non-specialty hospitals among racial groups by outpatient-inpatient index admission status. Multivariate logistic regression models were used to estimate the odds of using the NCI-CCC versus local nonspecialty hospitals. We considered non-linearity and interaction terms. The two logistic regression models we estimated satisfied the convergence criterion $(\mathrm{GCOV}=1 \mathrm{E}-8)$, and the likelihood ratio test for global null hypothesis for beta $=0$ has a $p$ value of $<0.001$. Both models satisfied the Hosmer and Lemeshow test for goodness-of-fit (the $p$ values were 0.16 for the outpatient data and 0.09 for the inpatient data) [10]. The estimated odds ratios were considered statistically significant for $p$ values less than $5 \%$ or if the $95 \%$ confidence intervals (CI) exclude 1. Data analysis for this study was conducted in SAS software version 9.2 [11].

\section{Results}

Table 1 shows frequency distributions of cancer patients by patient race/ethnicity, age, gender, health insurance coverage status, cancer diagnosis, treatment years, and the location of the treatment facility. Statistics in the table show that there were significantly more male cancer patients than female patients in the study population. The numbers of cancer patients significantly increase after age 50 and up to age 70 years, after which there is an observed small decline up to age 80 and a steep decline from age 80 onwards. The frequency estimates also show that the numbers of patients with MROC diagnosis were significantly higher than the numbers of patients with FROC and OTHER diagnoses. These patterns were observed among all of the ethnic groups in this study. Furthermore, the statistics in the table show that there were significantly more White patients with Medicare, Medicare HMO and Medicare PPO (Insur1), commercial and self-paid insurance (Insur3) in the study population. Data in Table 1 show that only 7 and $4.7 \%$ of the patients with MROC, FROC, and OTHER diagnoses treated at the NCI-CCC were Black and Hispanic, respectively. Patients of Other ethnicities accounted for $8.9 \%$ of 
Table 1 Frequency distributions (count [row percentage]) of cancer patients by race, gender, age, insurance, cancer diagnosis, treatment years, and facility location

\begin{tabular}{|c|c|c|c|c|c|}
\hline & & \multicolumn{4}{|c|}{ Patient race/ethnicity } \\
\hline & & $\begin{array}{l}\text { Black } \\
2537(8.65)\end{array}$ & $\begin{array}{l}\text { White } \\
23,843 \text { (81.27) }\end{array}$ & $\begin{array}{l}\text { Hispanic } \\
1345(4.58)\end{array}$ & $\begin{array}{l}\text { Others } \\
1613(5.50)\end{array}$ \\
\hline \multirow[t]{2}{*}{ Gender } & Male & $1889(9.58)$ & $15,841(80.37)$ & $889(4.51)$ & $1091(5.54)$ \\
\hline & Female & $648(6.73)$ & $8002(83.11)$ & $456(4.74)$ & $522(5.42)$ \\
\hline \multirow[t]{6}{*}{ Age } & Below 40 & $71(13.45)$ & $354(67.05)$ & $57(10.80)$ & $46(8.71)$ \\
\hline & $40-49$ & $159(9.53)$ & $1251(75.00)$ & $140(8.39)$ & $118(7.07)$ \\
\hline & $50-59$ & $630(11.43)$ & $4260(77.30)$ & $253(4.59)$ & $368(6.68)$ \\
\hline & $60-69$ & $925(9.20)$ & $8089(80.48)$ & $463(4.61)$ & $574(5.71)$ \\
\hline & $70-79$ & $601(7.31)$ & $6889(83.75)$ & $350(4.25)$ & $386(4.69)$ \\
\hline & 80 and above & $151(4.50)$ & $3000(89.45)$ & $82(2.44)$ & $121(3.61)$ \\
\hline \multirow[t]{5}{*}{ Insurance } & Insurl $^{\mathrm{a}}$ & $1175(7.40)$ & $13,367(84.22)$ & $590(3.72)$ & $740(4.66)$ \\
\hline & Insur $2^{\mathrm{b}}$ & $155(19.11)$ & $475(58.57)$ & $136(16.77)$ & $45(5.55)$ \\
\hline & Insur $3^{c}$ & $1072(9.28)$ & $9210(79.74)$ & $520(4.50)$ & $748(6.48)$ \\
\hline & Insur $4^{\mathrm{d}}$ & $28(7.12)$ & $272(69.21)$ & $40(10.18)$ & $53(13.49)$ \\
\hline & Insur5 ${ }^{\mathrm{e}}$ & $107(15.03)$ & $519(72.89)$ & $59(8.29)$ & $27(3.79)$ \\
\hline \multirow[t]{3}{*}{ Diagnosis } & FROC & 607 (6.69) & $7548(83.13)$ & $422(4.65)$ & $503(5.54)$ \\
\hline & MROC & $1880(9.58)$ & $15,778(80.37)$ & $885(4.51)$ & $1089(5.55)$ \\
\hline & OTHER & $50(7.99)$ & $517(82.59)$ & $38(6.07)$ & $21(3.35)$ \\
\hline \multirow[t]{7}{*}{ Treatment year } & 2005 & $206(6.84)$ & $2533(84.12)$ & $128(4.25)$ & $144(4.78)$ \\
\hline & 2006 & $348(7.12)$ & $4058(83.04)$ & $296(6.06)$ & $185(3.79)$ \\
\hline & 2007 & $424(7.95)$ & $4296(80.60)$ & $256(4.80)$ & $354(6.64)$ \\
\hline & 2008 & $466(8.44)$ & $4465(80.90)$ & 255 (4.62) & $333(6.03)$ \\
\hline & 2009 & $504(10.16)$ & $3878(78.19)$ & $263(5.30)$ & $315(6.35)$ \\
\hline & 2010 & $394(10.24)$ & 3157 (82.09) & $89(2.31)$ & $206(5.36)$ \\
\hline & 2011 & 195 (10.92) & $1456(81.57)$ & $58(3.25)$ & $76(4.26)$ \\
\hline \multirow[t]{7}{*}{ Facility location } & Highlands & $47(7.95)$ & $500(84.60)$ & $27(4.57)$ & $17(2.88)$ \\
\hline & Hillsborough ${ }^{\mathrm{f}}$ & $883(12.71)$ & $5091(73.25)$ & $615(8.85)$ & 361 (5.19) \\
\hline & NCI-CCI & $522(7.00)$ & $5926(79.42)$ & 349 (4.68) & $665(8.91)$ \\
\hline & Manatee & $94(6.49)$ & $1301(89.85)$ & $29(2.00)$ & $24(1.66)$ \\
\hline & Pasco & $53(1.96)$ & $2551(94.24)$ & $45(1.66)$ & $58(2.14)$ \\
\hline & Pinellas & $436(7.92)$ & $4739(86.05)$ & $85(1.54)$ & 247 (4.49) \\
\hline & Polk & $502(10.74)$ & $3735(79.93)$ & $195(4.17)$ & $241(5.16)$ \\
\hline
\end{tabular}

FROC female reproductive organs cancers, MROC male reproductive organs cancers, OTHER other cancer diagnoses

${ }^{a}$ Medicare, Medicare HMO, and Medicare PPO

${ }^{\mathrm{b}}$ Medicaid and Medicaid HMO

${ }^{\mathrm{c}}$ Commercial insurance, commercial HMO, commercial PPO, and self-pay

'Workers' compensation, charity, and other

${ }^{\text {e }}$ CHAMPUS, VA, state/local government, and Kidcare

${ }^{\mathrm{f}}$ Only patients from non-specialty hospitals are included in this category

the total NCI-CCC MROC, FROC, and OTHER diagnoses population. These estimates meant that $79.4 \%$ of patients with MROC, FROC, and OTHER diagnoses in Florida's regions 5 and 6 were treated at local non-specialty hospitals.

Table 2 shows results of tests of difference in mean age of cancer outpatients and inpatients treated at the NCI-CCC and other non-specialty facilities in Florida's regions 5 and 6 . Test results indicate that throughout the entire study period, the inpatients and outpatients treated at the NCI-CCC were younger and the differences between their ages and the ages of similar cancer patients treated at non-specialty local hospitals were statistically significant $(p<0.0001)$.

Statistics in Table 3 show that during the study years, the proportion of African American patients at the NCI-CCC was 
Table 2 Difference in mean age of cancer outpatients and inpatients treated at the NCI-CCC and other non-specialty facilities in Florida's Regions 5 and 6

\begin{tabular}{|c|c|c|c|c|}
\hline Year & $\begin{array}{l}\text { CCC } \\
\text { Mean (SD) } \\
(n)\end{array}$ & $\begin{array}{l}\text { Other } \\
\text { Mean (SD) } \\
(n)\end{array}$ & $t$ value & $p$ \\
\hline \multicolumn{5}{|c|}{ Outpatients } \\
\hline 2005 & $\begin{array}{l}66.33(11.11) \\
925\end{array}$ & $\begin{array}{l}69.08(10.50) \\
2086\end{array}$ & 6.39 & $<0.0001$ \\
\hline 2006 & $\begin{array}{l}64.95(10.94) \\
892\end{array}$ & $\begin{array}{l}69.33(10.70) \\
2076\end{array}$ & 10.15 & $<0.0001$ \\
\hline 2007 & $\begin{array}{l}64.67(10.44) \\
1002\end{array}$ & $\begin{array}{l}69.25(10.25) \\
2280\end{array}$ & 11.71 & $<0.0001$ \\
\hline 2008 & $\begin{array}{l}63.48(11.22) \\
970\end{array}$ & $\begin{array}{l}69.33(10.75) \\
2607\end{array}$ & 14.30 & $<0.0001$ \\
\hline 2009 & $\begin{array}{l}62.90(11.37) \\
1006\end{array}$ & $\begin{array}{l}68.45(10.88) \\
2150\end{array}$ & 13.16 & $<0.0001$ \\
\hline 2010 & $\begin{array}{l}66.61(9.80) \\
589\end{array}$ & $\begin{array}{l}69.88(9.37) \\
1440\end{array}$ & 7.03 & $<0.0001$ \\
\hline \multicolumn{5}{|c|}{ Inpatients } \\
\hline 2006 & $\begin{array}{l}59.67(9.97) \\
328\end{array}$ & $\begin{array}{l}63.88(12.34) \\
1591\end{array}$ & 6.66 & $<0.0001$ \\
\hline 2007 & $\begin{array}{l}59.71(10.06) \\
391\end{array}$ & $\begin{array}{l}64.14(11.66) \\
1657\end{array}$ & 7.58 & $<0.0001$ \\
\hline 2008 & $\begin{array}{l}60.57(10.88) \\
316\end{array}$ & $\begin{array}{l}64.26(12.09) \\
1626\end{array}$ & 5.42 & $<0.0001$ \\
\hline 2009 & $\begin{array}{l}59.95(10.85) \\
332\end{array}$ & $\begin{array}{l}63.78(11.89) \\
1471\end{array}$ & 5.70 & $<0.0001$ \\
\hline 2010 & $\begin{array}{l}61.69(9.74) \\
350\end{array}$ & $\begin{array}{l}64.27(11.83) \\
1467\end{array}$ & 4.26 & $<0.0001$ \\
\hline 2011 & $\begin{array}{l}60.12(10.62) \\
361\end{array}$ & $\begin{array}{l}63.98(11.92) \\
1424\end{array}$ & 6.02 & $<0.0001$ \\
\hline
\end{tabular}

significantly less than the proportion of African American patients at non-specialty hospitals in Florida's regions 5 and 6. Overall, for the outpatient dataset, the proportions of African American at the NCI-CCC and other non-specialty hospitals in the two regions were respectively 7.2 and $8.9 \%$, and for the inpatient dataset, the proportions were respectively 6.5 and $9.8 \%$. The proportions of inpatient and outpatient Hispanics were significantly less than those for White and African Americans at the NCI-CCC and non-specialty hospitals in the two regions (for the outpatient dataset, the proportions at the NCI-CCC and other non-specialty hospitals were respectively 4.6 and $4.4 \%$, and for the inpatient dataset, the proportions were respectively 4.9 and $4.7 \%$ ). We also found that the proportions of patients of Other races admitted at the NCICCC (Asians, Pacific Islanders, Native Indians, etc.), were significantly higher than those for African and Hispanic Americans (in the outpatient and inpatient datasets, the proportions at the NCI-CCC were 9.6 and $7.1 \%$, respectively). The proportions of outpatients and inpatients of Other races admitted at non-specialty hospitals were lower and very similar to the proportions for Hispanic Americans (4.4\% in the outpatient dataset and $4.2 \%$ in the inpatient dataset, respectively). White Americans accounted for 78.6 and $81.5 \%$ of the NCI-CCC's total cancer outpatient and inpatient populations, respectively. They accounted for 82.4 and $81.2 \%$ of the cancer outpatient and inpatient populations treated at local non-specialty hospitals.

To understand the association of the demographic and other characteristics of a patient with the likelihood of being treated at either the NCI-CCC or non-specialty hospitals in the two Florida health regions, we fitted two identical logistic regression models to the outpatient and inpatient datasets. The covariates used for the models were patient race/ethnicity, age, gender, health insurance payer type, facility region, principal diagnosis, and treatment year (2005-2010 for outpatient data and 2006-2011 for the inpatient data). Model estimation results are displayed in Table 4.

Estimates from the model for the outpatient dataset show an odds ratio of 0.958 for the age of cancer outpatients treated at the NCI-CCC versus non-specialty hospitals when adjusted for MROC. Overall, for each 1-year incremental increase in age, the odds of being treated at the NCI-CCC were reduced by $4.2 \%$ for outpatients with MROC diagnoses. However, the age-adjusted odds of receiving treatment at the NCI-CCC versus local non-specialty hospital were significantly higher for male outpatients. Younger males were more likely to receive 
Table 3 Differences in the percentage of cancer patients by race/ethnic treatment facility for Florida counties in Regions 5 and 6

\begin{tabular}{|c|c|c|c|c|c|c|c|}
\hline \multirow[b]{3}{*}{ Year } & \multirow[b]{3}{*}{ Race } & \multicolumn{3}{|c|}{ Outpatient data } & \multicolumn{3}{|c|}{ Inpatient data } \\
\hline & & \multicolumn{3}{|c|}{ Treatment facility } & \multicolumn{3}{|c|}{ Treatment facility } \\
\hline & & $\mathrm{CCC}$ & Other & $\chi^{2}(p)$ & $\mathrm{CCC}$ & Other & $\chi^{2}(p)$ \\
\hline \multirow[t]{4}{*}{2005} & Black & 5.30 & 7.53 & $42.00(<0.0001)$ & - & - & \\
\hline & White & 80.97 & 85.52 & & - & - & \\
\hline & Hispanic & 5.73 & 3.60 & & - & - & \\
\hline & Other & 8.00 & 3.36 & & - & - & \\
\hline \multirow[t]{4}{*}{2006} & Black & 5.83 & 7.80 & $28.32(<0.0001)$ & 4.27 & 7.54 & $4.80(0.1872)$ \\
\hline & White & 80.27 & 84.10 & & 85.98 & 82.59 & \\
\hline & Hispanic & 7.17 & 4.87 & & 6.40 & 6.91 & \\
\hline & Other & 6.73 & 3.23 & & 3.35 & 2.95 & \\
\hline \multirow[t]{4}{*}{2007} & Black & 6.39 & 8.42 & $108.77(<0.0001)$ & 6.65 & 8.57 & $24.82(<0.0001)$ \\
\hline & White & 76.65 & 82.11 & & 79.28 & 81.23 & \\
\hline & Hispanic & 3.49 & 5.66 & & 2.56 & 4.95 & \\
\hline & Other & 13.47 & 3.82 & & 11.51 & 5.25 & \\
\hline \multirow[t]{4}{*}{2008} & Black & 6.08 & 9.01 & $43.36(<0.0001)$ & 6.96 & 9.23 & $4.38(0.2233)$ \\
\hline & White & 79.79 & 81.97 & & 79.11 & 80.20 & \\
\hline & Hispanic & 3.40 & 3.99 & & 7.28 & 5.84 & \\
\hline & Other & 10.72 & 5.02 & & 6.65 & 4.74 & \\
\hline \multirow[t]{4}{*}{2009} & Black & 10.44 & 9.95 & $34.56(<0.0001)$ & 9.64 & 10.39 & $23.29(<0.0001)$ \\
\hline & White & 74.06 & 79.67 & & 72.59 & 80.10 & \\
\hline & Hispanic & 4.97 & 5.40 & & 6.93 & 5.03 & \\
\hline & Other & 10.54 & 4.98 & & 10.84 & 4.48 & \\
\hline \multirow[t]{4}{*}{2010} & Black & 9.68 & 10.42 & $00.32(0.9564)$ & 5.14 & 11.52 & $14.98(0.0018)$ \\
\hline & White & 81.66 & 80.69 & & 87.14 & 82.41 & \\
\hline & Hispanic & 2.21 & 2.36 & & 2.00 & 2.39 & \\
\hline & Other & 6.45 & 6.53 & & 5.71 & 3.68 & \\
\hline \multirow[t]{4}{*}{2011} & Black & - & - & & 6.65 & 12.01 & $11.03(0.0116)$ \\
\hline & White & - & - & & 84.49 & 80.83 & \\
\hline & Hispanic & - & - & & 4.71 & 2.88 & \\
\hline & Other & - & - & & 4.16 & 4.28 & \\
\hline \multirow{2}{*}{\multicolumn{2}{|c|}{$\begin{array}{l}\text { Mean \% Black } \\
\text { Mean \% White }\end{array}$}} & 7.2 & 8.9 & $190.45(<0.0001)$ & 6.5 & 9.8 & $49.03(<0.0001)$ \\
\hline & & 78.6 & 82.4 & & 81.5 & 81.2 & \\
\hline \multicolumn{2}{|c|}{ Mean \% Hispanic } & 4.6 & 4.4 & & 4.9 & 4.7 & \\
\hline \multicolumn{2}{|c|}{ Mean \% Other } & 9.6 & 4.4 & & 7.1 & 4.2 & \\
\hline
\end{tabular}

cancer treatment at the NCI-CCC than older males with similar MROC diagnoses.

The age-adjusted odds ratios for African American, Hispanic and Other race/ethnicity outpatients being treated at the NCI-CCC were respectively $0.63,0.70$, and 1.72 compared to White outpatients. That is, the odds of African and Hispanic American outpatients being treated at the NCI-CCC were respectively 37 and $30 \%$ less than the odds for White outpatients of the same age, while the odds of outpatients of Other races being treated at the NCI-CCC were $72 \%$ higher than those for White outpatients with similar diagnoses.

Outpatients with Medicare, Medicare HMO, or Medicare PPO health insurance were at greater risk of not being treated at the NCI-CCC. The estimates in Table 4 show that outpatients who have worker's compensation, charity, unknown, or other types of health insurance coverage are 6.52 times more likely to be treated at the NCI-CCC compared to cancer outpatients who have Medicare and Medicare HMO or Medicare PPO health insurance. However, the odds of outpatients with Medicare, Medicare HMO, or Medicare PPO health insurance being treated at the NCI-CCC were better than those for outpatients who carry CHAMPUS, VA, other state/local government, or Kidcare insurance. These outpatients were 0.093 times as likely as Medicare, Medicare HMO, or Medicare PPO-insured outpatients to receive treatment at the NCI-CCC. These estimates were adjusted for age, gender, race, facility region, principal diagnosis, and year of treatment. 
Table 4 Odds of seeking treatment at a comprehensive cancer center (CCC) versus nonspecialty hospitals in regions 5 and 6, State of Florida

${ }^{\text {a }} C L$ confidence limits

\begin{tabular}{llll}
\hline Variable & & $\begin{array}{l}\text { Outpatient data } \\
\text { Point estimate }(\mathrm{CL})^{\mathrm{a}}\end{array}$ & $\begin{array}{l}\text { Inpatient data } \\
\text { Point estimate (CL) }\end{array}$ \\
\hline Demographics & Age & $0.958(0.949,0.967)$ & $0.927(0.909,0.945)$ \\
& Gender (M vs F) & $2.304(0.890,5.967)$ & $1.719(0.560,5.282)$ \\
Ethnicity & Black vs White & $0.625(0.548,0.712)$ & $0.521(0.425,0.638)$ \\
& Hispanic vs White & $0.700(0.592,0.829)$ & $0.604(0.473,0.771)$ \\
& Other vs White & $1.724(1.496,1.987)$ & $1.517(1.208,1.904)$ \\
Insurance status & Insur2 vs Insur1 & $1.070(0.822,1.394)$ & $0.997(0.447,2.226)$ \\
& Insur3 vs Insur1 & $1.087(0.983,1.202)$ & $0.955(0.681,1.340)$ \\
Insur4 vs Insur1 & $6.515(4.398,9.652)$ & $1.565(0.424,5.776)$ \\
Cancer diagnosis & Insur5 vs Insur1 & $0.093(0.055,0.157)$ & $0.159(0.047,0.539)$ \\
PROC vs MROC & $5.417(2.080,14.103)$ & $2.130(0.690,6.578)$ \\
Treatment years & OTHER vs MROC & $0.984(0.423,2.288)$ & $2.081(0.734,5.901)$ \\
Outpatient & Fac region (CCC vs 5 and 6) & $<0.001(<0.001,>999)$ & $<0.001(<0.001,>999)$ \\
2006 vs 2005 & Inpatient & & \\
2007 vs 2005 & 2007 vs 2006 & & \\
2008 vs 2005 & 2008 vs 2006 & $0.938(0.825,1.066)$ & $1.794(1.131,2847)$ \\
2009 vs 2005 & 2010 vs 2006 & $0.782(0.691,0.885)$ & $4.351(2.837,6.672)$ \\
2010 vs 2005 & 2011 vs 2006 & $0.639(0.565,0.723)$ & $4.216(2.736,6.497)$ \\
\hline & & $0.748(0.660,0.848)$ & $4.821(3.140,7.402)$ \\
& & $0.789(0.687,0.906)$ & $4.537(2.964,6.943)$ \\
\hline
\end{tabular}

Furthermore, the age-adjusted odds ratio of being treated at the NCI-CCC for outpatients with female reproductive organ cancers (FROC) was 5.42 times that of outpatients with male reproductive organ cancers (MROC). However, lower odds for receiving cancer treatment at the NCI-CCC versus local non-specialty hospitals were observed for outpatients with OTHER cancer diagnoses when compared with outpatients diagnosed with male reproductive organ cancers (MROC). Overall, we did not find further improvements in the likelihood of outpatients being treated at the NCI-CCC for years following the dataset's index year (2005). Among cancer outpatients in regions 5 and 6 , the odds of receiving treatment at the NCI-CCC versus local non-specialty hospitals were lower for all years following year 2005.

The model fitted to the inpatient dataset (Table 4) shows an odds ratio of 0.93 for the age of inpatients treated at NCI-CCC when evaluated for Medicare, Medicare HMO, or Medicare PPO health insurance coverage status (Insur1) and being male. That is, for a 1-year incremental increase in age the odds of being treated at NCI-CCC were reduced by $7 \%$ for male inpatients with Medicare, Medicare HMO, and Medicare PPO (Insur1) insurance coverage. Statistics in the table also show that the odds of receiving treatment at the NCI-CCC versus local non-specialty hospital were significantly higher for male cancer inpatients.

The adjusted odds ratios of African American, Hispanic, and Other race/ethnicity inpatients being treated at NCICCC were respectively $0.52,0.60$, and 1.52 versus that of
White inpatients. That is, the adjusted odds for an African American and Hispanic inpatient to be treated at NCI-CCC were respectively 48 and $40 \%$ less than those for a White inpatient, while the adjusted odds for inpatients of Other races were $48 \%$ higher than those for their White counterparts.

Compared to inpatients with Medicare and Medicare HMO or Medicare PPO health insurance (Insur1), the statistics in Table 4 show that only inpatients who carried workers' compensation, charity, and other types of health insurance (Insur4) had higher age-adjusted odds of being treated at the NCI-CCC than at non-specialty hospitals. The age-adjusted odds ratios of being treated at the NCI-CCC for inpatients who carried Medicaid and Medicaid HMO (Insur2), commercial insurance, commercial HMO, commercial PPO and self-pay (Insur3), and CHAMPUS, VA, other state/local government or Kidcare insurance (Insur5) were lower than those for inpatients with Medicare and Medicare HMO or Medicare PPO insurance coverage (Insur1).

The age-adjusted odds ratios of receiving treatment at the NCI-CCC versus local non-specialty hospitals for out/ inpatients with FROC diagnoses were significantly higher than those for similar out/inpatients diagnosed with MROC. Patients with OTHER cancer diagnoses have significantly higher odds of receiving treatment at the NCI-CCC than MROC patients only when admitted as inpatients. The estimates in Table 4 also show that among cancer inpatients in Florida's regions 5 and 6 , the odds of receiving treatment at 
the NCI-CCC were significantly higher for all years following 2006 (the index year of the inpatient dataset).

\section{Discussion}

Compared to White patients with similar cancer diagnoses, African American and Hispanic cancer patients had significantly lower odds of receiving treatment and care at the NCI-CCC. Statistics from the hospital discharge datasets (Table 1) indicate that between 2005 and 2011, approximately $70 \%$ of Hispanic and African American patients (65 and $74 \%$, respectively) with MROC, FROC, and OTHER cancer diagnoses in the seven counties constituting Florida's regions 5 and 6 sought diagnostic, treatment, and care services at non-specialty hospitals. Approximately 67 and $30 \%$ of White cancer patients and cancer patient of Other races made the same choice. The discharge data (Table 3) also revealed that African Americans who made up about $16.0 \%$ of the total population of the State of Florida (about $15 \%$ in 2005 and $16.5 \%$ in 2011) and about $10 \%$ of the total population of the seven counties adjacent to the NCICCC (about $9.5 \%$ in 2005 and $10.8 \%$ in 2011) were underrepresented in the cancer inpatient and outpatient populations served at the NCI-CCC. From 2005 to 2011, only $7.2 \%$ of the outpatients and $6.5 \%$ of the inpatients who were treated for MROC, FROC and OTHER cancers at the NCI-CCC were African American. The number for Hispanic Americans who represented well over $10 \%$ of the total population in the two regions during the study years (approximately $8 \%$ in Pinellas and Pasco counties and $20 \%$ of the populations in Hardee, Highlands, Hillsborough, Manatee, and Polk counties) were significantly lower. Only $4.6 \%$ of the outpatients and $4.9 \%$ of the inpatients treated for MROC, FROC, and OTHER cancers at the NCI-CCC were of Hispanic origin (Table 3). The underrepresentation of African Americans and Hispanics in the cancer patient populations served at the NCI-CCC is not seen in the case of White Americans. The latter group respectively accounted for 78.6 and $81.5 \%$ of the NCI-CCC's total MROC, FROC, and OTHER cancers outpatient and inpatient populations (Table 3). These estimates approximate the representation of Whites in the state and study county populations. In contrast, outpatient and inpatient African Americans treated for MROC, FROC, and OTHER cancers at non-specialty hospitals in the study regions averaged about 9 and $10 \%$ of patients with similar diagnoses who were treated at the same facilities (Table 3). This is an approximate representation of African Americans in the total populations of the study regions.

The findings of this study indicate that despite its designation as a NCI-CCC and the availability of evidence which suggests better treatment, surgical and survival outcomes for a number of cancers at NCI-designated comprehensive cancer centers [3, 4], significant portions of local African American and Hispanic cancer patients did not take advantage of the much wider range of cancer treatment and care services provided by the NCI-CCC considered in this study. Instead, they received treatment and care at local non-specialty medical facilities. This is puzzling because information from the datasets used in this study indicate that the NCI-CCC provided more cancer diagnosis, treatment, and care services than every other non-specialty hospital in the study regions (Fig. 1). We expected that despite overall declines in cancer incidence and mortality among African and Hispanic Americans [12], the significantly higher cancer incidence and mortality burdens among African Americans [13], and the fact that, since 2009, cancer surpassed heart disease as the leading cause of death among Hispanics [14] were sufficient reasons for patients from these ethnicities to seek treatment at the NCICCC. Our data show that they did not. We do not have data which explained why African American and Hispanic MROC, FROC, and OTHER cancer patients were more likely to choose non-specialty hospitals for cancer treatment. We suspect that part of the explanation may lie in the higher cost of treatment at the NCI-CCC compared to non-specialty hospitals.

The significant mean age differences were also puzzling findings which we cannot adequately explain due to lack of information. However, the data we analyzed clearly showed that the NCI-CCC treated patients who were significantly younger than patients with similar cancer diagnoses who were treated at non-specialty hospitals. The consistency of the significant age differences in both the inpatient and outpatient datasets implies the possibility of the presence of either institutional practices which imposed strong access barriers which discouraged older cancer patients or internal operational processes which enabled the NCI-CCC to consistently select for treatment mostly patients who were significantly younger than patients with similar cancer diagnosis in the regional total cancer population. Also, longer travel distance to the NCICCC may have contributed to lower use of the facility by older patients. The only study which examined the impact of travel distance found that "living farther away from an NCI setting predicted a lower odds of use for all populations" [6]. However, the NCI-CCC which we have examined provided free transportation for the elderly (Fig. 1). This leads us to speculate that travel distance might not have been the primary determining factor in deterring older cancer patients from using the NCI-CCC.

Another notable finding from the data analysis are the significantly larger numbers (almost twice as many) of male than female cancer patients across all racial/ethnic groups (Table 1). This could be directly attributed to the types of cancers we examined in this study, or indirectly to the possibility is under-diagnosis of breast cancer among women. 


\begin{tabular}{|c|c|c|c|c|c|c|c|c|c|c|c|c|c|c|c|c|c|c|c|c|c|c|c|c|c|c|c|c|c|c|c|c|c|}
\hline & 3 & 15 & 27 & 33 & 34 & 424 & 43 & 44 & 45 & 53 & 58 & 60 & 65 & 68 & 88 & 899 & 909 & 91 & 92 & 93 & 949 & 95 & 969 & 97 & 989 & 99 & 100 & 101 & 102 & 109 & 115 & 120 & 122 \\
\hline \multicolumn{34}{|l|}{ Hillsborough Hospitals } \\
\hline $\mathrm{NCl}-\mathrm{CCC}$ & 1 & 1 & 1 & 1 & 1 & 1 & 1 & 1 & 1 & 1 & 1 & 1 & 1 & 1 & 1 & 1 & 1 & 1 & 1 & 1 & 1 & 1 & 1 & 1 & 1 & 1 & 1 & 1 & 1 & 1 & 1 & 1 & 1 \\
\hline UNIV COMM at CARROLL & 1 & 1 & 1 & 1 & 1 & & 1 & & 1 & & 1 & 1 & 1 & 1 & 1 & 1 & & & 1 & 1 & & & & 1 & 1 & & 1 & & & 1 & & & 1 \\
\hline TAMPA GENERAL HOSP & 1 & 1 & 1 & 1 & 1 & & 1 & 1 & 1 & 1 & 1 & 1 & 1 & 1 & 1 & 1 & & & 1 & 1 & & & & 1 & 1 & & & & & 1 & & 1 & \\
\hline UNIV COMM HOSPITAL & 1 & 1 & 1 & 1 & 1 & & 1 & & 1 & & 1 & 1 & 1 & 1 & 1 & 1 & & & 1 & 1 & & & & 1 & 1 & & 1 & & & 1 & & & 1 \\
\hline MEMORIAL HOSP OF TAMPA & 1 & 1 & & & & & & & & & 1 & 1 & & 1 & 1 & & & & 1 & 1 & & & 1 & 1 & 1 & & & & & 1 & & & \\
\hline BRANDON REGIONAL & 1 & 1 & 1 & & & & 1 & & & 1 & 1 & 1 & 1 & 1 & 1 & 1 & & & 1 & 1 & & & & 1 & 1 & & & & & & & & 1 \\
\hline \multicolumn{34}{|l|}{ Pasco Hospitals } \\
\hline FLORIDA HOSP ZEPHYRHILLS INC & 1 & 1 & & 1 & & & 1 & & & & & 1 & & & 1 & 1 & & 1 & 1 & 1 & & & & 1 & 1 & & & & & 1 & & & \\
\hline REG MED CENT BAYONET POINT & 1 & 1 & & & & & 1 & & & 1 & 1 & & 1 & 1 & 1 & 1 & & & 1 & & & & & & 1 & & & & & 1 & & & \\
\hline \multicolumn{34}{|l|}{ Pinellas Hospitals } \\
\hline BAYFRONT MED CENTER INC & 1 & 1 & 1 & 1 & 1 & & 1 & 1 & 1 & 1 & 1 & 1 & 1 & 1 & 1 & 1 & & 1 & 1 & 1 & 1 & 1 & & 1 & 1 & 1 & 1 & 1 & 1 & 1 & & & \\
\hline ST PETE GENERAL HOSP & 1 & 1 & 1 & 1 & & & 1 & & & & & 1 & 1 & 1 & 1 & 1 & & & & 1 & & 1 & 1 & 1 & 1 & & & & & 1 & & & \\
\hline NORTHSIDE HOSPITAL & 1 & & & 1 & & & & & 1 & & & 1 & & 1 & 1 & 1 & & & 1 & 1 & 1 & & & & 1 & & & & & & & & \\
\hline ALL CHILDREN'S HOSP & 1 & & 1 & 1 & 1 & & 1 & 1 & 1 & 1 & 1 & & 1 & 1 & 1 & 1 & & & 1 & 1 & & & & 1 & 1 & & & & & 1 & 1 & & \\
\hline
\end{tabular}

Fig. 1 Service availability at the NCI-CCC and select non-specialty hospitals in three surrounding counties. Checked boxes above indicate availability of the numerical service code listed on the top row. The following is a listing of each numerical code followed by its description: 3 airborne infection isolation room; 15 breast cancer screening/mammogram; 15 chemotherapy; 33 community outreach; 34 complementary medicine; 42 hospice program; 43 pain management; 44 palliative care program; 45 enrollment assistance services; 53 hemodialysis; 58 linguistic/translation services; 60 medical surgical intensive care center; 65 nutrition programs; 68 oncology services; 88 ct scanner; 89 diagnostic radioisotope facility; 90 electron beam computed tomography (EBCT); 91 full-field digital mammography; 92 magnetic resonance imaging (MRI); 93 multi-slice spiral computed tomography (MSCT); 94 64+slice CT; 95 PET; 96 PET/CT; 97 SPECT; 98 ultrasound; 99 image-guided radiation therapy (IGRT); 100 intensity-modulated radiation therapy (IMRT); 101 shaped beam radiation system; 102 stereotactic radiosurgery; 109 social work services; 115 bone marrow transplant; 120 tissue transplant; 122 transportation to health services for the elderly
National cancer statistics typically show significantly larger numbers of men in new genital and urinary systems cancer diagnoses categories. The larger numbers of male patients with MROC and MROC-related diagnoses which we found were consistent with national trends. However, national data also show significantly larger numbers of women in new breast cancer diagnoses, typically presented as a separate diagnosis category and not combined with genital or urinary systems cancers. Adding the numbers of breast cancer diagnoses among females to the respective estimates of genital and urinary systems, cancers drastically reduces the disparities in the total estimates of these cancer diagnoses among men and women [15]. Though we included female breast cancer and female breast-related cancers while deriving the numbers for female patients across racial/ethnic categories, the statistics showing significant disparities in the total numbers of male and female cancer patients which we presented in Table 1 do not follow national trends. Since we examined index admissions and primary diagnoses to rule out duplication, we can only assume that the disparities in the numbers of male and female patients are an indirect outcome of under-diagnoses of breast and breast-related cancers among the females in Florida's regions 5 and 6.

\section{Conclusions}

The findings of previous research on health disparities improved our understanding of the pathways through which poverty and low socioeconomic status, institutional, primary healthcare provider, and patient variables account for lower levels of access to available healthcare services among ethnic minority patients in general, and lower cancer survival outcomes among African Americans in particular. For instance, former studies suggest that African American patients are more likely than White patients to concentrate in lower-end health insurance plans [16], to be treated by primary care providers with less clinical training and who may have less referral access to specialty facilities and important clinical resources than physicians treating White patients [17]. Other studies suggest that African Americans are also more likely to report a general mistrust of the healthcare industry and of medical/biomedical research and experimentation, present at clinical settings with later disease stages at diagnosis and show a tendency towards refusing participation in medical/ biomedical experiments [18-21]. African American patients are also more likely than other patients to show a heightened sense of ethnic prejudice directed against them in clinical 
settings and in racially discordant healthcare provider-patient interactions $[16,22]$. They are more likely to delay or avoid getting cancer screening due to perceived racial or ethnicbased discrimination at clinical settings, fear of a positive cancer diagnosis, or news of poor prognosis [16, 20, 23-25]. A few studies suggest that patients in general are more likely to use nearby healthcare facilities regardless of the quality of care these facilities provide, and that only a very small percentage of minority cancer patients opt to seek treatment at a NCIdesignated cancer center $[6,26]$.

Though some of these findings support the substantive interpretations of the results of our analysis showing lower percentages of African Americans and Hispanics in the total cancer patient population at the NCI-CCC, they also provide evidence which suggests that the explanations of the underrepresentation of these ethnicities in the NCI-CCC's patient population may have to do with patient attitudes, psychological predispositions, and the referral abilities and interests of their primary care providers. However, previous research did not adequately answer a crucial question: what factors enable a NCI-CCC to consistently treat significantly younger cancer patients, more patients with commercial/private health insurance coverage, more men, and disproportionately lower numbers of African American and Hispanic cancer patients? This is a fundamental question which requires an examination of the NCI-CCC's outreach policies and practices, treatment costs, and internal operational processes. Such an assessment is especially important in light of a number of significant research findings. Previous studies indicate that healthcare providers who treat minority patients face barriers to practice privileges at specialty hospitals. They also typically encounter difficulties when attempting to access specialists, costly imaging technologies, and nonemergency hospital admissions for their patients [17]. We do not have data which show the extent of access to the NCI-CCC that local primary care providers have and, as such, we cannot make a final determination if referral and other access difficulties are the root cause of the low numbers of African American and Hispanic patients in the NCI-CCC's total cancer population. However, the significantly low numbers of African Americans and Hispanics in the NCI-CCC's patient population and the findings of prior research suggest the need for designing ways to better accommodate primary care providers who typically treat minority and low-income patients [17]. Furthermore, previous studies also suggest that the likelihoods of cancer survival and better treatment outcomes among African Americans are significantly increased if they received treatment and medical care of the same quality as that received by Whites [27-30]. Coupled with research findings indicating that patients treated at NCIdesignated cancer centers experience lower cancer surgical mortality and superior medical care outcomes [3-5], the evidence presented in this study which shows a significantly wider range of quality cancer treatment and care services at the study NCI-CCC in comparison with non-specialty local hospitals (Fig. 1) points to a strong potential that this facility produces patient outcomes at levels similar to those at NCICCCs elsewhere. Therefore, the evidence which we presented to show significantly low representation of African Americans and Hispanics at the study NCI-CCC suggests the need for a more aggressive and sustained minority cancer patient recruitment effort. The study NCI-CCC has a community outreach program (Fig. 1) which may have to be re-engineered or, if necessary, better resourced to affect significant African American and Hispanic cancer patient uptake.

Despite research findings that only small percentages of African American and Hispanic cancer patients used NCIdesignated cancer centers [6], failure of these highly specialized cancer treatment facilities to attract African American and Hispanic patients has yet to be presented as an institutional problem. Minority patients' preferences, predilections, predispositions, and barriers to specialized care that are encountered by their primary healthcare providers are thought to explain their underrepresentation in the population treated at NCIdesignated cancer centers [16, 20, 22-26]. However, NCIdesignated cancer centers and CCCs have institutional hierarchies and service pricing practices identical to those of large business corporations. The thought pattern which attributes underrepresentation to the behaviors of minority patients and the their primary care providers ignores an increasingly prevalent requirement that large business systems whose existence relies mainly on consumers and the provision of services to clients must demonstrate appropriate corporate social responsibility and corporate citizenship [31-34]. In the case of NCIdesignated cancer centers and CCCs, this means demonstrable success in attracting and retaining minority patients at levels higher than or, at minimum, equal to their representations in the general population. However, we expect the ability of NCI-CCCs to attract the relatively poor African American and Hispanic patients to be tempered by two important reasons: that important or lengthy cancer treatments provided at NCI-CCCs are expensive and likely to be beyond the patients' financial reach and that the health insurance policies these patients typically have (including some Medicare HMOs) do not cover treatment at major cancer treatment facilities, including NCI-designated cancer centers. Both of these reasons require a number of important national healthcare policy changes that are not the immediate focus of this paper.

The results of this study have other important implications. Though the NCI-CCC we examined has a number of community outreach programs, it has consistently failed to attract minority patients. It also failed to attract older patients. Both demographic groups experience heavier cancer incidence and, in the case of some cancers, heavier mortality burdens. As we noted earlier in this paper, more targeted marketing and outreach efforts at both community and provider levels are required to increase the uptake of patients (with eligible health 
insurance coverage) from these groups into the NCI-CCC's total patient population. However, even if the study NCI-CCC implements these recommendations and extends more practice and referral privileges to physicians treating ethnic minority and older patients, we expect the potential creation of local accountable care organizations (ACOs) as an outcome of the implementation of the Affordable Care Act (ACA) [35] to reduce the numbers of African American, Hispanic, and older patients at the NCI-CCC. The ACOs are based on a healthcare delivery and payment model in which reimbursement to healthcare providers is dependent on particular quality metrics and reductions in the total charges for care delivered to an assigned group of patients $[35,36]$. The economies of scale which are inherent in the ACOs design concept suggest progressive improvements in the quality of care, reductions in treatment costs, and a strong potential for meeting the ACA's quality mandates for higher reimbursements. The ethnic, age, and insurance groups largely excluded from the patient populations at the NCI-CCC are the primary ACA targets for the care advantages created by ACOs $[35,36]$. Our data show that patients from these groups have primarily been treated at nonspecialty hospitals. The potential for coordinated higher quality care at ACOs implies stronger potential for retaining the substantial patient market share collectively held now by nonspecialty hospitals and a stronger potential for increased demand for care by minority and older patients. The economic disadvantages typically experienced by members of these groups predict their choice of affordable care which the ACOs are likely to provide. This choice is likely to be strengthened with patients' knowledge (or positive perception due to advertisement and community outreach campaigns) of coordinated higher quality care likely to be provided by ACOs.

\section{Limitations}

The findings of this study are tempered by a few limitations. The datasets which we used did not provide measures of patient preferences or indications of shifts in these preferences. As such, we cannot ascertain the extent of the accuracy of our predictions of lower patient volumes at the study NCI-CCC as consequences of the enactment of the ACA and the emergence of ACOs. Though previous studies have indicated that cancer patients are unlikely to travel long distances to NCIdesignated centers for treatment, our data does not contain measures for travel distance. Therefore, we could not compare the study patients to patients elsewhere in terms of travel distance preferences. Also, our analysis was limited to MROC, FROC, and OTHER cancer patients only. Future studies may benefit from assessments of other common cancers. In addition, we only studied patients in the counties surrounding the NCI-CCC. This limits our ability to generalize our findings to patients from other Florida counties. Furthermore, though we examined patients at index admissions for primary cancer diagnoses to rule out duplication, we suspect that some patients may have been counted more than once in the analysis. However, we expect the number of these patients to be insignificant and, therefore, to not affect the nature of the outcomes of statistical analysis. To our knowledge, the datasets we used provide the only comprehensive patient discharge data on all reporting hospitals in the two regions we chose for this study as well as for the entire State of Florida. It has been widely used in peer reviewed published research on a variety of healthcare and health outcomes issues. We are confident that the results which we derived from the datasets have a high degree of accuracy and are informative.

Conflict of Interest The authors declare that they have no conflict of interest.

Informed Consent This study did not involve human subjects. It examined public-use secondary data which had been de-identified by the agency which provided the data. The study did not require Institutional Review Board approval.

Animal Studies No animal or human studies were carried out by the authors for this article.

\section{References}

1. National Cancer Institute. NCI-Designated Cancer Centers. http:// www.cancer.gov/aboutnci/budget planning leg/plan-2013/cancercenters. Accessed 18 Jun 2014.

2. National Cancer Institute. NCI-Designated Cancer Centers. http:// www.cancer.gov/researchandfunding/extramural/cancercenters/ about. Accessed 18 Jun 2014.

3. Paulson EC, Mitra N, Sonnad S, et al. National Cancer Institute designation predicts improved outcomes in colorectal cancer surgery. Ann Surg. 2008;126:318-29.

4. Birkmeyer NJO, Goodney PP, Stukel TA, Hillner BE, Birkmeyer JD. Do cancer centers designated by the National Cancer Institute have better surgical outcomes? Cancer. 2005;103:435-41.

5. Merkow RP, Bentrem DJ, Chow WB, Ko CY, Bilimoria KY. Can we measure the quality of complex cancer surgery? Comparison of patients and outcomes at National Cancer Institute Designated Cancer Centers (NCI-CC) vs Non-NCI centers. J Am Coll Surg. 2012;215: S104.

6. Huang LC, Ma Y, Ngo JV, Rhoads KF. What factors influence minority use of National Cancer Institute-designated cancer centers? Cancer. 2014;120(3):399-407. doi:10.1002/cncr.28413.

7. Florida Cancer Data System. Available at http://fcds.med.miami.edu/ inc/welcome.shtml

8. Florida Agency for Health Care Administration. Available at http:// www.fdhc.state.fl.us/

9. National Cancer Institute. Common Cancer Types. Available at http:// www.cancer.gov/cancertopics/types/commoncancers. Accessed 19 Jun 2014

10. Hosmer DW, Lemeshow S. Applied logistic regression. 2nd ed. New York: Wiley; 2000.

11. SAS Institute Inc. SAS Software Version 9.2. Cary, NC: SAS Institute Inc., 2008. 
12. Siegel R, Naishadham D, Jemal A. Cancer statistics, 2012. CA Cancer J Clin. 2012;62(1):10-29. doi:10.3322/caac.20138.

13. National Cancer Institute. Fact Sheet: Cancer Health Disparities. http:/www.cancer.gov/cancertopics/factsheet/disparities/cancerhealth-disparities. Accessed 25 Aug 2014.

14. Siegel R, Naishadham D, Jemal A. Cancer statistics for Hispanics/ Latinos, 2012. CA Cancer J Clin. 2012;62(5):283-98. doi:10.3322/ caac. 21153 .

15. Jemal A, Siegel R, Ward E, Hao Y, Xu J, Thun MJ. Cancer statistics, 2009. CA Cancer J Clin. 2009;59:225-49.

16. Smedley BD, Stith AY, Nelson AR, editors. Unequal treatment: confronting racial and ethnic disparities in healthcare. Washington, DC: The National Academy Press; 2003.

17. Bach PB, Pham HH, Schrag D, Tate RC, Lee HJ. Primary care physicians who treat blacks and whites. N Engl J Med. 2004;351(6):57584 .

18. Allen JD, Kennedy M, Wilson-Glover A, Gilligan TD. AfricanAmerican men's perceptions about prostate cancer: implications for designing educational interventions. Soc Sci Med. 2007;64(11): 2189-200.

19. Talcott JA, Spain P, Clark JA, Carpenter WR, Do YK, Hamilton RJ, et al. Hidden barriers between knowledge and behavior: the North Carolina prostate cancer screening and treatment experience. Cancer. 2007;109(8):1599-606.

20. Airhihenbuwa CO, Liburd L. Eliminating health disparities in the African American population: the interface of culture, gender and power. Health Educ Behav. 2006;33(4):488-501.

21. Gilligan T. Social disparities and prostate cancer: mapping the gaps in our knowledge. Cancer Causes Control. 2005;16(1):45-53.

22. LaVeist TA, Nickerson KJ, Bowie JV. Attitudes about racism, medical mistrust, and satisfaction with care among African American and white cardiac patients. Med Care Res Rev. 2000;57(Supplement 1): 146-61.

23. Crawley LM, Ahn DK, Winkleby MA. Perceived medical discrimination and cancer screening behaviors of racial and ethnic minority adults. Cancer Epidemiol Biomark Prev. 2008;17(8):1937-44.
24. Durant RW, Legedza AT, Marcantonio ER, Freeman MB, Landon BE. Different types of distrust in clinical research among whites and African Americans. J Natl Med Assoc. 2011;103:123-30.

25. Scharff DP, Mathews KJ, Jackson P, Hoffsuemmer J, Martin E, Edwards D. More than Tuskegee: understanding mistrust about research participation. J Health Care Poor Underserved. 2010;21:879-97.

26. Finlayson SR, Birkmeyer JD, Tosteson AN, Nease RF. Patient preferences for location of care: implications for regionalization. Med Care. 1999;37:204-9.

27. Bach PB, Schrag D, Brawley OW, Galaznik A, Yakren S, Begg CB. Survival of blacks and whites after a cancer diagnosis. JAMA. 2002;287(16):2106-13.

28. Shavers VL, Brown ML. Racial and ethnic disparities in the receipt of cancer treatment. J Natl Cancer Inst. 2002;94(5):334-57.

29. Komenaka IK, Martinez ME, Pennington Jr RE, et al. Race and ethnicity and breast cancer outcomes in an underinsured population. J Natl Cancer Inst. 2010;102(15):1178-87.

30. Pearce JA, Doh J. The high impact of collaborative social initiatives. MIT Sloan Manag Rev. 2005;46(3):30-9.

31. Smith NC. Corporate social responsibility: whether or how? Calif Manag Rev. 2003;45(4):52-76.

32. Low L, Kalafut PC. Invisible advantage: how intangibles are driving business performance. Cambridge: Perseus Publishing; 2002.

33. World Business Council for Sustainable Developmen. Corporate social responsibility: make good business sense. Conches-Geneva: World Business Council for Sustainable Development; 2000.

34. Murray KB, Vogel CM. Using a hierarchy of effects approach to gauge the effectiveness of CSR to generate goodwill toward the firm: financial versus nonfinancial impacts. J Bus Res. 1997;38:141-59.

35. Davis K, Abrams M, Stremikis K. How the Affordable Care Act will strengthen the nation's primary care foundation. J Gen Intern Med. 2011;26(10):1201-203.

36. Davis K, Guterman S, Collins SR, et al. Starting on the path to a high performance health system: analysis of the payment and system reform provisions in the Patient Protection and Affordable Care Act of 2010. Publication No. 1442. New York: The Commonwealth Fund; 2010. 